\title{
LATIFÚNDIO: UMA ANÁLISE A PARTIR DO ARCABOUÇO NORMATIVO DO REGIME DE SESMARIAS NO BRASIL
}

\author{
Karla Karoline Rodrigues Silva ${ }^{1}$ \\ Cláudio Lopes Maia
}

\section{RESUMO}

O latifúndio, constituído sob a vigência do período sesmarial, possui como característica a produção de monoculura voltada à exportação e, por esta razão, fomentou a existência de conflitos entre os posseiros que tinham como um dos pressupostos o cultivo da terra ou a ausência dele. $O$ estudo possui como enfoque a análise da formação do latifúndio apresentando como marco histórico e, sobretudo jurídico, o regime das sesmarias a fim de averiguar se sua constituição pode ser embasada pelas normas contidas nos regulamentos que trataram sobre as sesmarias. A metodologia adotada é o dedutivo por meio da investigação teórico-bibliográfica e legal-normativa.

Palavras-chave: regime de sesmarias, modelo jurídico-normativo, latifúndio, posse, conflito agrário

\section{LATIFÚNDIO: AN ANALYSIS OF THE SET OF LAWS ABOUT SESMARIAS' REGIME IN BRAZIL}

\begin{abstract}
The latifúndio, constituted under the term of the sesmarial period, has as a characteristic the production of export-oriented monoculture and, for this reason, it fomented the existence of conflicts between the squatters who had as one of the presuppositions the cultivation of the land or the absence of it. The study focuses on the analysis of the formation of latifundia, presenting as a historical and, above all, legal framework, the regime of the sesmarias in order to ascertain if their constitution can be based on the norms contained in the regulations that deal with the sesmarias. The methodology adopted is the deductive through theoreticalbibliographic and legal-normative research.
\end{abstract}

Keywords: regime of sesmarias, legal-normative model, legislation, possession, latifúndio

\footnotetext{
${ }^{1}$ Mestranda em Direito Agrário pela Universidade Federal de Goiás (UFG). Pós-graduada em Direito Constitucional pelo Instituto Brasiliense de Direito Público (IDP), Direito Civil e Processual Civil pela FCV (20182019) e Direito Administrativo pela FCV (2018-2019). Graduada em Direito pela Pontifícia Universidade Católica de Goiás (PUC-GO). Bolsista do Programa Universidade para Todos.

E-mail: karla.s.rodrigues@hotmail.com

${ }^{2}$ Doutor em História pela Universidade Federal de Goiás, UFG (2008), Mestre em História Universidade Federal de Goiás, UFG (2000), Graduado em História pela Pontifícia Universidade Católica de Goiás, PUC - GO (1992), Atualmente é Associado I da Universidade Federal de Goiás, onde atua no Curso de História vinculado ao Departamento de História e Ciências Sociais, Campus Catalão e no Mestrado em Direito Agrário, Faculdade de Direito. Tem experiência na área de História e Direito, com ênfase em História das Sociedades Agrárias, conflitos agrários e questão agrária, atuando principalmente nos seguintes temas: movimentos sociais no campo, teoria da história, movimentos sociais no cerrado, história regional e estado, pluralismo jurídico e direito agrário. E-mail: maiaclaudio@yahoo.com.br
} 


\section{INTRODUÇÃO}

O processo de reconhecimento do território brasileiro foi iniciado por Portugal, uma vez que os primeiros atos normativos que regulamentaram a utilização da terra no Brasil são oriundos do direito português, o sistema de sesmarias.

O regime de sesmarias foi o instrumento utilizado pela metrópole para fixar seu poder sobre seus colonos e estabelecer o modo de aproveitamento de um terreno desconhecido, como era o Brasil. Como é cediço, o sistema em questão já era aplicado no território português, razão pela qual, no início da colonização, a pretensão foi transpor as sesmarias tal como implementada em Portugal, medida que foi frustrada diante de características próprias das terras brasileiras.

A pesquisa sobre as sesmarias revela-se importante, porquanto o aludido instituto foi o primeiro modelo jurídico-normativo imposto ao Brasil enquanto colônia, bem como por ser a origem de toda uma construção histórica do direito de propriedade agrária no país.

Ordinariamente, o período colonial de ocupação do território brasileiro é caracterizado pelo latifúndio, enquanto polo da agricultura destinada à exportação e a utilização da mão-de-obra escrava, instrumento de produção. E é neste ponto que reside o objeto de investigação do presente trabalho que é voltado para compreensão da formação do latifúndio, entendido como um dos grandes propulsores dos conflitos agrários ainda na atualidade, a partir da análise das normas que regulamentavam as sesmarias.

Neste ponto, a realização de um estudo fundado no conjunto legislativo que regulamenta determinado exercício de direitos perpassa pela compreensão de que a elaboração da lei teve como objetivo mediar as relações entre as diversas forças sociais que compõem a comunidade para a qual foi criada (SILVA, 2008).

Assim, a legislação sobre o regime sesmarial foi o instituto normativo usado para mediar as relações entre a metrópole e o senhoril rural da colônia, de modo que a interpretação das normas extraídas deste conjunto legislativo é fundamental para o exame do processo de concessão de sesmarias e, em consequência, a formação do latifúndio, como fenômeno jurídico na história ${ }^{3}$.

Sob esta perspectiva, Laura Beck Varela (2005, p. 85) traz relevante contribuição ao tema ao dizer que a busca da especificidade do jurídico tem como objetivo "visualizar as formas jurídicas em sua articulação com a dinâmica dos interesses sociais. Sobre o direito como discurso e como espaço social de produção desse discurso e do exercício da autoridade jurídica, em relativa dependência quanto às demandas externas". Não se pretende, desta forma, afastar o direito da política e a história do direito da história geral. 
Desta forma, tem-se como problema jurídico: a constituição do latifúndio pode ser justificada pelo aparato normativo que regulamentou o regime de sesmarias no Brasil?

Apresenta-se como objetivos o estudo acerca do período de implementação do sistema de sesmarias no Brasil-colônia, o processo de concessão das sesmarias, o conjunto de legislações vigente à época e as implicações que as normas deste regime provocaram na formação do latifúndio no Brasil.

A metodologia adotada no presente trabalho é o dedutivo e, para tanto, utiliza-se, a investigação teórico-bibliográfica e legal-normativa. O estudo possui como marco teórico os ensinamentos de vários estudiosos sobre a temática, sobretudo Márcia Maria Menendes Motta, Lígia Osório Silva, Ruy Cirne Lima e Laura Beck Varela que auxiliam no estudo em conjunto dos aspectos históricos e jurídicos do regime de sesmarias.

Em um primeiro momento, foram realizadas algumas considerações sobre as distinções entre o regime sesmarial de Portugal e aquele imposto à colônia. No segundo momento, tem-se o exame acerca de algumas legislações sobre as sesmarias promulgadas e revogadas durante o período colonial. Por fim, busca-se o estudo direcionado ao latifúndio na perspectiva da análise dos dispositivos legais que regulamentaram o período histórico de sua constituição no Brasil, o regime das sesmarias.

\section{A IMPLEMENTAÇÃO DO SESMARIALISMO NO BRASIL}

O primeiro instituto jurídico adotado pela Coroa de Portugal para viabilizar a colonização territorial no Brasil foram as sesmarias ${ }^{4}$.

O sistema sesmarial foi criado em Portugal em 1375 pelo rei D. Fernando I, cujo objetivo foi regulamentar a distribuição de terras comunais destinadas à produção agrícola. Significa dizer que as sesmarias foram utilizadas como instrumento de reestruturação do sistema fundiário português diante da crise na agricultura enfrentada pelo país, marcada por guerras, doenças e fome (MOTTA, 2012).

Neste contexto, Roberto Smith (1990, p. 517-518) salienta que:

A Lei das Sesmarias deve ser entendida dentro do quadro que decorre da grande desestruturação por que passou a organização da propriedade fundiária em Portugal, após a peste de 1348-50, que despovoou o campo e gerou grandes áreas

\footnotetext{
$4 \quad$ O conceito de sesmarias ainda é muito discutido. Acerca do tema, Lígia Osório Silva (2008) ensina que sesmarias vem do latim caesinae cuja tradução significa cortes ou rasgões na superfície da terra. Por outro lado, há aqueles que sustentam a tese de que sesmarias deriva do verbo dividir ou demarcar terras, bem como da palavra sesmo ou sesma que representava a sexta parte de qualquer coisa. Por fim, sesmaria também poderia representar o magistrado municipal encarregado de distribuir a terra.
} 
abandonadas. Significa também o fato de que ela visava a regulamentar o uso e a exploração das extensas terras estatais e da Igreja. A Lei das Sesmarias deve ser entendida, portanto, dentro do quadro geral de um sistema produtivo que o Estado pretendia organizar, a partir de uma forma de domínio condicionado.

Laura Beck Varela (2005), neste contexto, acrescenta que a sesmaria foi uma forma de apropriação da terra condicionada ao dever jurídico do cultivo, tendo como primeiro regulamento normativo a Lei Agrária de Dom Fernando I, em 1375. Esclarece, ainda, que mesmo após as transformações da sociedade portuguesa, o dever jurídico do cultivo foi mantido pelas Ordenações do Reino.

Vê-se, portanto, que a Lei de Sesmarias foi elaborada diante de um cenário em que, apesar de serem ocupadas, as terras de Portugal não eram cultivadas. Tal elemento, aliado a escassez de alimentos, fomentou a elaboração da legislação em voga, de modo a por fim a ociosidade das terras, obrigando os senhorios a cultivarem sob pena de perda de seu domínio (SILVA, 2008).

Ao tomar posse das terras brasileiras, a Coroa de Portugal estabeleceu o referido sistema que perdurou entre o período de 1534, com a constituição das Capitanias Hereditárias, a 1822, com a independência do país.

De início, tinha-se a pretensão de aplicar a lei das sesmarias da mesma maneira que se deu em Portugal. Lígia Osório Silva (2008) descreve este momento histórico ao dizer que o sesmarialismo português sofreu várias adaptações a fim de se amoldar à realidade da colônia, caracterizando o que a autora denominou como sesmarialismo colonial. Neste mesmo sentido, Costa Porto (1965) afirma que a lei de sesmarias não foi transmutada integral e puramente de Portugal ao Brasil, eis que a semelhança entre metrópole e colônia era apenas a existência de um solo sem aproveitamento.

Márcia Maria Menendes Motta (2012) esclarece que as distinções do instituto das sesmarias entre metrópole e a colônia são motivadas pelas características próprias do Brasil, como a ausência de trabalhadores aptos a exercerem a exploração da terra na forma determinada por Portugal, uma vez que, àquela época, o Brasil era ocupado por indígenas que exploravam a terra em condições diferenciadas das pretendidas pelos portugueses. A extensão territorial brasileira também se apresentou como um entrave à aplicação do instituto na forma portuguesa, porquanto os donatários concentravam-se nas sedes do território e não conheciam a dinâmica de ocupação do interior da colônia.

Assim, a constituição da sesmaria em Portugal é voltada para a ocupação de terras não cultivadas, os homens não trabalhavam a terra, enquanto que no Brasil-colônia a lei de 
sesmarias visava à ocupação de terras virgens e novas, não havia homens para trabalhar na terra.

Em outras palavras significa dizer que, na metrópole, a pretensão das sesmarias era reorganizar o sistema fundiário e a atividade agrícola por meio da fixação do homem na terra. Ocorre que o referido procedimento tornou-se inviável nas terras da colônia, pois, no século XIV, não havia no Brasil qualquer estrutura para discutir eventuais medidas de exploração.

Tal circunstância levou Portugal a adaptar o instituto às necessidades socioeconômicas da colônia. As adaptações foram implementadas a partir da criação de uma estrutura administrativa colonial, fundada, mormente, na intenção de organizar as atividades do Brasil de modo a alicerçar o poderio comercial de Portugal diante dos demais países europeus (SILVA, 2008).

A lei de sesmarias, originalmente pensada para ocupação de terras não cultivadas, na colônia, tornou-se um conjunto de normas jurídicas para solidificar a colonização, configurando-se como um instrumento de força da Coroa sobre seus colonizados (MOTTA, 2012).

Virgínea Rau (1982), de forma semelhante, ensina que ao agraciar os colonos com terras de titularidade de Portugal, exigindo-lhe a obrigação de produzir e o recolhimento de tributos, as sesmarias representava um verdadeiro meio coercitivo de impor o poder e influência direta da Coroa em uma sociedade que ainda estava em formação.

\section{SESMARIAS: INSTRUMENTO JURÍDICO}

A partir do estudo sobre a implementação do instituto sesmarial no Brasil-colônia necessário se faz sua abordagem legislativa para melhor compreendê-lo enquanto fenômeno jurídico. Isso se revela importante porque as sesmarias representaram o período de criação das primeiras disposições legais aplicadas no território brasileiro, vale dizer, as primeiras legislações que discriminaram o poder da metrópole lusitana exercido sobre seus súditos sulamericanos que estabeleceram limites e disciplinaram o uso da terra.

Neste ponto, Antônio Carlos Wolkmer (2003) afirma que o Direito ${ }^{5}$ apresentado ao Brasil não foi fruto de uma evolução da experiência comunitária, mas sim de um processo

\footnotetext{
${ }^{5} \mathrm{O}$ Direito, ora destacado, entre as mais variadas concepções, segue aquela relacionada à legalidade, segundo o qual Roberto Lyra Filho (1999, p. 4) explica como sendo o Direito aprisionado "em conjunto de normas estatais, isto é, de padrões de conduta impostos pelo Estado, com a ameaça de sanções organizadas (meios repressivos expressamente indicados com órgão e procedimento especial de aplicação)". O referido autor, no entanto, seguindo as teses do marxista italiano Gramsci, critica esta acepção do pensamento acerca do Direito, destacando
} 
colonizador fortemente influenciado pelos interesses da metrópole portuguesa que agiam, nos termos denominados pelo autor, como os "donos do poder".

Wolkmer (2003) esclarece, ainda, que o projeto capitaneado pela metrópole é caracterizado pela imposição, em uma região habitada por indígenas, de um sistema de legalidade considerada avançada sob o ponto de vista do controle e da efetividade formal herdada do Direito Romano.

Desta forma, o aludido autor nos ensina que o Direito Português constituiu-se a base legislativa do Direito pátrio e, em consequência, da nossa formação jurídica. É neste cenário que se destaca o relevante papel das sesmarias no processo de construção do Brasil enquanto colônia e, mais tarde, Estado independente.

A legislação das sesmarias, promulgada em 1375, foi regulamentada e editada pelas Ordenações do Reino de Portugal: Afonsinas (1446), Manuelinas (1521) e Filipinas (1603). Entre as alterações ocorridas neste período, Carmem Alveal (2011) destaca o conceito de sesmeiro enquanto distribuidor de terras, estipulação de prazo para os beneficiários com as concessões de sesmarias cultivassem as terras concedidas e para verificação da utilização da terra, inovaram, ainda, quanto à fiscalização das sesmarias.

As Ordenações, portanto, marcaram o período inicial das sesmarias. Neste ponto, Lígia Osório Silva (2008) argumenta que a gratuidade e a condicionalidade da doação foram as principais características desta fase do sesmerialismo colonial, haja vista que as Ordenações estabeleciam que as concessões de terras deveriam ser feitas de maneira gratuita, sujeitas tão somente ao pagamento de dízimo a Deus. Por outro lado, a condicionalidade estava prevista na cláusula de aproveitamento e na exigência de registrar a carta de doação. Esta característica era representada pelo dever de se produzir na terra, denominado como princípio da obrigatoriedade do cultivo ${ }^{6}$, conforme os interesses da metrópole.

Ocorre que, embora as Ordenações tenham sido um importante instrumento normativo do sistema sesmarial, a referida legislação discriminava apenas sobre a concessão de terras, revelando-se omissa com relação à terra. Por esta razão, os estudiosos sobre o tema

que o Direito deve ser estudado a partir de uma visão dialética abrangendo normas não-estatais de grupos e povos oprimidos, devendo, também, preocupar-se com os aspectos históricos de sua formação.

${ }^{6}$ Em sua obra, Laura Beck Varela (2005, p. 33-34) ensina que o princípio da obrigatoriedade do cultivo remete à "mentalidade possessória (...), modelo antropológico que parte das coisas, ao invés do sujeito, numa perspectiva não-individualista, parte de um concepção teleológica da natureza". A autora, fazendo referência aos postulados de Paolo Grossi, explica que esta mentalidade de várias formas de apropriação ou de plúrimas propriedades representa a figura do domínio útil que "indica a atribuição de um conteúdo ao conceito romano, conteúdo que se vincula à efetividade da utilização do bem. Atesta o reinado da efetividade e a impossibilidade de uma fórmula abstrata, de um vínculo puro de relações entre o homem e as coisas. Expressão da "utilidade" na forma de domínio sesmarial, é precisamente, a obrigatoriedade de cultivo". 
são uníssonos ao asseverar que o regime de sesmarias foi articulado a partir de um extenso conjunto de normas, de modo que outras legislações foram elaboradas para sanar as lacunas deixadas pelas Ordenações, como decretos, alvarás, cartas forais e outros.

A edição de novas legislações acerca das sesmarias, para além da relação de poder da metrópole sobre a colônia, demonstra que as leis até então vigentes não correspondiam às pretensões para as quais foram criadas, tornaram-se obsoletas diante das demandas da nova conjuntura social que, no cenário das sesmarias, são traduzidas por meio dos conflitos decorrentes da ocupação do território brasileiro, mormente no que diz respeito à distribuição e formação de grandes propriedades de terras.

É neste contexto que os fatos históricos ocorridos no Brasil-colônia, em meados do século XVIII, constituem-se como elemento de estudo do presente trabalho, na medida em que fomentaram a constante atuação do legislador em inovar o regime de sesmarias.

Desta forma, longe de se fazer mera descrição do contexto histórico em que se deram as mutações das sesmarias, revela-se inviável tratar sobre o processo de transformação legislativo das sesmarias sem fazer referências à história, mesmo porque, nas palavras de Wolkmer (2003, p. 16) há uma estreita relação entre a História e o Direito "principalmente quando se tem em conta a percepção da normatividade extraída de um determinado contexto histórico definido como experiência pretérita que conscientiza e liberta o presente".

Márcia Maria Menendes Motta (2012), de maneira sucinta e clara, descreveu algumas das mais importantes alterações legislativas que remontam o período sesmarial. Expõe a autora que no início da colonização do Brasil, a lei de sesmarias não especificava as datas de suas concessões, a exemplo das normas contidas nas Ordenações do Reino. Em seguida, adotaram medidas de restrição das áreas a serem concedidas, uma vez que, em grande parte, as terras concentravam-se em mãos dos parentes dos donatários, distribuidores de terras nas capitanias hereditárias, com isso surgiram muitos conflitos pela distribuição e posse de terras.

A metrópole promulgou a legislação denominada Provisão de 20 de outubro de 1753 que estabeleceu duas normas: a) a revalidação das datas das permissões dos sesmeiros que cultivassem as terras e, b) autorização para os sesmeiros pedirem novas datas de terras despovoadas desde que não excedam 3 (três) léguas de comprido e 1(um) de largo. Desta forma, a Provisão significou uma tentativa de intervir e controlar o processo de ocupação territorial da época, preocupando-se também em solucionar os conflitos oriundos desta ocupação. 
Motta (2012) destaca a transição do período em que a estipulação de limite de terras tornou-se relevante ao salientar que, no início do regime das sesmarias, este aspecto era desconsiderado para fins de colonização, mas, ao final do século XVIII, a limitação passou a ser uma obrigatoriedade, pois era um instrumento para impedir conflitos de terras, principalmente em áreas muito ricas como as capitanias hereditárias de Minas Gerais e Rio de Janeiro.

Após experiência da Provisão de 20 de outubro e 1753, foi promulgada a Lei da Boa Razão (1769). Como é cediço, a Coroa Portuguesa detinha o poder de definir quem tinha o domínio sobre as terras que eram concedidas aos colonos por meio de um documento, denominado carta de sesmarias ${ }^{7}$.

A Lei da Boa Razão estabeleceu como requisitos à concessão das cartas de sesmarias o cultivo da terra e a antiguidade de ocupação. Observa-se, pois, que os encargos supracitados foram definidos pelos usos e práticas jurídicas locais com a finalidade de proteger os interesses daqueles cultivavam a terra.

Neste ponto, a lei em questão desempenhou papel de destaque entre as legislações do regime sesmarial, pois conferiu status de texto legal ao costume da posse de terras. Mais do que isso, houve o reconhecimento de um ato praticado cotidianamente segundo os interesses e benefícios dos colonos. Para Thompson (1998, p. 86) isso se justifica, pois o costume é o elo existente entre a lei e a prática agrária, eis que "podemos considerá-lo como práxis e igualmente como lei. A sua fonte é a práxis.” Assim, a interpretação e aplicação dos costumes deveria ser um fenômeno comum na elaboração das legislações.

Todavia, a configuração da posse como costume e os conflitos existentes na época, representaram ameaça ao poder dos detentores de terras de grandes extensões. Isso porque tais detentores mantinham a posse, mas não cultivavam toda a área sobre a qual pleiteavam a concessão das sesmarias.

Neste período, criaram outra norma de grande destaque no sistema de sesmarias: o Alvará de 1795, que representou uma das últimas tentativas da metrópole de unificar e organizar a legislação sobre as sesmarias, porquanto, segundo o que preleciona Gonçalves Chaves (1978 apud VARELA, 2005 p. 105) “uma tão grande variedade e contraditória porção de cartas régias, avisos, disposições, ordens, provisões, alvarás e decretos sobre sesmarias,

\footnotetext{
${ }^{7}$ Importante salientar que o termo "domínio", na conjuntura retratada no presente trabalho, significa meramente o direito de estar sobre a terra e dela usufruir. Portanto, não guarda relação com ser ou não proprietário, eis que, à época das sesmarias, não havia uma concepção de propriedade da terra na forma prevista no artigo 1.228 , do Código Civil que hoje conhecemos.
} 
com tanta derrogação e ampliação, que seria quase impossível determinar o sentido da lei a semelhante respeito".

Esta lei estabelece como requisitos à concessão das sesmarias: a) delimitação e demarcação de terras da serem pleiteadas, b) registro na Contadoria de Junta da Real Fazenda, c) reserva de parte das terras para caminhos públicos, d) a concessão de sesmarias não incluía a riqueza do solo. Acresça-se a isso a implementação de um mecanismo de fiscalização e fixação de uma légua de terras como extensão máxima para as concessões próximas a centros urbanos (VARELA, 2005).

Ainda no contexto, convém destacar o Decreto de 22 de junho de 1808, que determinava que a concessão das sesmarias fossem realizadas pelo Desembargo de Paço, no Rio de Janeiro e o Alvará de 25 de janeiro de 1809, cuja ordem era a vedação de concessão sesmarial sem que houvesse medição judicial por sentença transitada em julgado.

O regime de sesmarias foi extinto por meio da Resolução de 17 de julho de 1822, norma que suspendeu a expedição das cartas de doações. O referido ato normativo que foi editado a partir do pedido do posseiro Manoel José dos Reis, de Minas Gerais, que se insurgia contra a concessão de sesmarias em terras que ocupava há mais de vinte anos (VARELA, 2005).

É importante ressaltar que houve uma passagem muito abrupta para o fim do regime sesmarial. Em outras palavras significa dizer que as sesmarias foram adaptadas à Colônia, período em que houve tentativa da Coroa para disciplinar o processo de ocupação e exploração das terras brasileiras, bem como a preocupação de cobrar pelo uso delas.

Neste ponto, assevera Ruy Cirne de Lima $(2002)^{8}$ que, após a suspensão da concessão de sesmarias, inicia-se no Brasil o período denominado por ele como "regime de posses" que durou até a Lei de 1850, que se apresentava como "mero apossamento de terrenos para exploração agrícola e pecuária, praticado por grandes e pequenos” (GORENDER, 1988, p. 397).

\section{SISTEMA SESMARIAL E O FUNDAMETO DO LATIFÚNDIO}

\footnotetext{
${ }^{8}$ Sobre este período, Ruy Cirne Lima (2002, p. 48) argumenta que a Resolução de 17 de julho de 1822 significou nada mais que confirmação de um fato consumado: "a instituição das sesmarias já havia rolado fora da órbita de nossa evolução social”.
} 
A análise da base legal do regime de sesmarias enquanto modelo jurídico que viabilizou a concessão de terras no território do Brasil-colônia nos revela que o uso deste bem estava condicionado a deveres jurídicos que eram alterados conforme a conjuntura colonial, isto é, os interesses da metrópole.

Como se sabe, o período colonial brasileiro é identificado pela formação do latifúndio e pela utilização de mão-de-obra escrava, elementos que juntos viabilizaram a produção na agricultura destinada à exportação. Sobre o período sesmarial, Laura Beck Varela (2005) aduz que, para além da historiografia, a compreensão da transposição do sistema sesmarial português para o território da colônia perpassa pela compreensão da política mercantilista que orientava as relações econômicas entre metrópoles europeias e colônias americanas.

À época do regime das sesmarias, a produção em alta era a cana-de-açúcar, cuja manutenção exigia grande extensão de terras e mão-de-obra escrava. Acerca deste período, Hebe Castro (1987, p. 118) aduz que a obtenção legal de sesmarias era relativamente fácil para aqueles que possuíam grande número de escravos. Prossegue dizendo que "a apropriação de uma extensão de terras muito maior do que as necessidades imediatas da lavoura consistiam em condição indispensável à possibilidade de reprodução ampliada da grande fazenda".

Nas palavras de Sérgio Buarque de Hollanda (1963, p. 25) a produção de grande lavoura na forma de monocultura, como ocorreu na época colonial, era entendida como "braço escravo e terra farta, terra para gastar e arruinar, e não para proteger ciosamente". Hollanda, claramente, afirma que o modelo jurídico das sesmarias viabilizou a formação do latifúndio nas terras da colônia.

Ruy Cirne Lima (2002, p. 40) sustenta a tese de que a legislação das sesmarias, em especial o Regimento de 17 de dezembro de 1548, fez vigorar no Brasil o "espírito latifundiário", segundo o qual apresentada como exigência para a concessão de terras para a construção de engenhos de cana de açúcar e estabelecimentos semelhantes, "posses bastantes para fazê-lo e ainda para elevar as torres e fortificações necessárias à defesa contra o gentio".

$\mathrm{O}$ autor faz uma crítica ao sistema normativo das sesmarias ao dizer que, além da aplicação isolada, as legislações foram elaboradas de maneira esparsa. O grande número de alvarás e decretos trouxe certa dificuldade de compreensão. Pontua, ainda, que (LIMA, 2002, p. 47):

Nos próprios quadros da época, todavia, a legislação e o processo das sesmarias se complicam, emaranham e confundem, sob a trama invencível da incongruência dos 
textos, da contradição dos dispositivos, do defeituoso mecanismo das repartições e ofícios de governo, todo reunido num amontoado constrangedor de dúvidas e tropeços. Assim, difusa e incerta, e nada sábia nas suas disposições, a legislação das sesmarias tristemente se celebrizou entre nós.

Apesar de diversos autores tratarem da relação direta entre latifúndio e sesmaria, a questão não parece tão simples. Isso se justifica porque, em grande parte da historiografia jurídica, a constituição do latifúndio é analisada a partir das concessões de terras com áreas extensas em prol da larga escala de produção de monocultura, o que, também, fomentou a permanência do escravismo.

Ocorre que nem todas as terras com áreas extensas eram cultivadas, daí surge a contradição da tese de que as sesmarias, enquanto instrumento jurídico normativo, foram o sustentáculo do latifúndio. Sanches (1996, p. 134) melhor explica sobre este período esclarecendo que "a constituição da grande propriedade é, pois, uma necessidade do sistema, não para impedir a pequena propriedade em si, mas o 'desvio' do uso da terra para atividades não mercantis".

Neste sentido, embora Lígia Osório Silva (2008) seja filiada à corrente que imputa ao regime de sesmarias a causa do latifúndio, a autora aponta alguns aspectos relevantes ao dizer que há outros modos de apropriação de grandes extensões de terra, como a posse, modalidade que esteve presente por todo o período sesmarial. Soma-se a isso o fato de que, ao tempo da extinção das concessões das sesmarias, apenas uma parcela pequena do território brasileiro estava apropriada.

Ressalte-se que a existência de parcelas de terras não aproveitadas nos remete a uma das principais características do regime de sesmarias: incerteza quanto à dimensão territorial. Ao longo de todo período colonial, percebe-se a intenção, por parte da metrópole portuguesa, de impor a limitação como um dever jurídico aos sesmeiros ${ }^{9}$. Tal preocupação é constante nos alvarás e decretos que regulamentavam as sesmarias, a exemplo daqueles citados no capítulo anterior.

Importante notar que as normas contidas nos instrumentos das sesmarias instituíram o dever do cultivo como instrumento jurídico à concessão de terras. Esta exigência legal ocasionou inúmeros conflitos entre os interesses da metrópole e da elite local, pois a obrigatoriedade do cultivo afastava a liberdade dos sesmeiros de gerir as terras que lhes foram concedidas. Este elemento representava nada mais que uma consequência do desenho jurídico

\footnotetext{
${ }^{9}$ Aliás, a dificuldade de identificar os limites é retratada nas várias cartas e requerimentos dirigidas à metrópole, como aquela escrita por Antônio Cabral de Mello, morador do Rio Grande. (VARELA, 2005).
} 
adotado no Brasil no período colonial caracterizado por uma propriedade sesmarial condicionada e não-absoluta sujeitas aos ditames da metrópole.

A crítica quanto ao número de legislação esparsa das sesmarias apontada por Ruy Cirne Lima apresenta-se pertinente. De fato, o período sesmarial foi marcado por intensa atividade legiferante da metrópole. Convém, contudo, destacar que a edição de decretos e alvarás foi motivada pela intenção de regulamentar as relações sociais travadas na colônia. Foram tentativas de reprimir atos arbitrários da administração responsável pela concessão das sesmarias e assegurar o cumprimento dos deveres jurídicos previstos em cada lei, atividade que, por sua vez, é inerente ao Estado e é externalizada por meio da imposição de normas.

Esta assertiva pode ser ratificada a partir da análise de um trecho do Alvará de 1795, ato normativo amplamente citado pelos estudiosos do tema e que, certamente, foi um dos principais da época colonial. O referido alvará inicia-se fazendo referência “(...) os abusos, irregularidades, e desordens que têm grassado estão e vão grassando em todo o Estado do Brasil, sobre a matéria das sesmarias, a mais importante, a mais útil e a mais conveniente aos comuns interesses (...) (VERELA, 2005, p. 105).”

A mencionada legislação pode ser utilizada para demonstrar o caráter rígido do arcabouço legal imposto à colônia. A exigência de vários deveres jurídicos aos sesmeiros provocou conflitos entre os interesses da "alta sociedade" local e o poder central da metrópole, o que ocasionou a precoce revogação do Alvará de 1795. Confira-se o excerto do Decreto de 10 de dezembro de 1796 que suspendeu a eficácia do alvará em questão:

\footnotetext{
Tendo-me sido presentes os embaraços e inconvenientes que podem resultar da imediata execução da sábia lei das sesmarias, que fui servido mandar publicar pelo meu Conselho de Ultramar, seja porque nas circunstâncias atuais não é o momento mais próprio para dar um seguro estabelecimento às vastas propriedades de meus vassalos nas províncias do Brasil; seja pela falta que há aí de geômetras, que possam fixar medições seguras, e ligadas inalteravelmente a medidas geométricas, e astronômicas, que só podem dar-lhes a devida estabilidade; seja finalmente pelos muitos processos, e causas que poderiam excitar-se, querendo pôr em execução tão saudáveis princípios e estabelecimentos, sem primeiro haver preparado tudo o que é indispensável, por bem determinar que o Conselho Ultramariano, suspenda por ora a execução e efeitos dessa saudável lei. (LINHADRES DE LACERDA, apud VARELA, 2005, p. 107).
}

Observa-se, desta forma, que as tentativas das normas do período sesmarial em regularizar o quadro fundiário que estava se formando na colônia foram frustradas diante das dificuldades que sua aplicação poderia provocar à elite colonial. 
Outrossim, para além da legislação das sesmarias, a análise da formação do latifúndio guarda estreita relação com a maneira pela qual era exercido o direito de uso da sesmarias. Como é cediço, o cultivo e a moradia habitual eram alguns dos fundamentos jurídicos que asseguravam a concessão de sesmarias. Todavia, a própria negligência dos fazendeiros em cumprir os deveres jurídicos que lhes formam impostos fomentaram os conflitos pela posse de terras. Os beneficiários das sesmarias, em grande parte, não delimitavam suas terras, pois tinha a pretensão de expandi-las (MOTTA, 1996). Esta constatação demonstra a ilegalidade perpetrada pelos fazendeiros no sentido de angariar para si a posse de terras que eram destinadas a outros sesmeiros ou, ainda, não havia sido objeto de concessão.

A prática do ato em questão, representada pela monopolização de parcelas de terras em mãos de poucas pessoas, tempos após a extinção do regime sesmarial, caracterizou o quadro latifundiário brasileiro que, na visão de Laura Beck Varela (2005, p. 117) significou:

(...) um complexo de situações, que só mais tarde seriam reguladas pela Lei n. 601, de 1850. Havia sesmarias concedidas e integralmente regularizadas - demarcadas, confirmadas e aprovadas (cultura ou criação), sobre as quais o concessionário tinha domínio sobre a gleba. Havia também as sesmarias em que os concessionários tinham só a posse, e não o domínio, pela ausência de algumas exigências legais. Também as glebas ocupadas por simples posses, sem título, eram situações de fato; ocupações com ou sem exploração. E, por fim, as terras sem ocupação (terras devolutas do império) - 'não concedidas ou já revertidas ao poder público, por não atendimento das exigências legais, se anteriormente objeto de concessão de sesmarias".

Da análise do que expõe do trecho da Varela, é possível compreender que a posse irregular de grandes extensões de terras, o latifúndio, não se deu por ausência de legislação que pudesse limitar esta ocupação, mesmo porque, no período sesmarial, alguns atos normativos foram rechaçados em decorrência do caráter rígido impregnado em suas normas, a exemplo do Alvará de 1795, discutido neste capítulo. Em verdade, o que se percebe é a falha no que tange à fiscalização das cartas concedidas, tarefa imputada ao governador e ao capitão geral (LIMA, 2002).

Neste ponto, Motta (2012) destaca um elemento comum no período de concessão de sesmarias nas capitanias do Maranhão, Piauí, Pará, Minas Gerais, Rio de Janeiro, São Pedro do Rio Grande do Sul. Segundo ela, embora a existência de lei própria, a concessão de sesmarias foram realizadas fora dos critérios legais, era simplesmente uma busca por riquezas, como o que ocorria na Capitania do Rio de Janeiro em que a concessão de sesmarias não obedecia a ordem legal de limitação de terras. 
Para exemplificar o contexto das concessões de sesmarias no Brasil, a autora destaca dois casos emblemáticos: Ignácio Pamplona e Garcia Paes Leme. Ambos foram importantes na colonização do sertão brasileiro. Eles chefiaram expedições de colonização. Motta (2012), em resumo, relata que as concessões pleiteadas por Ignácio Pamplona, em grande parte, foram concedidas, até mesmo aquelas pleiteadas por seus familiares. Na época, a ideia que os responsáveis pela análise do pedido de sesmaria passava era de que à medida que Pamplona ajudava na colonização do sertão, mais sesmarias lhe eram conferidas, não se importando se as normas do Alvará de 1795 eram ou não cumpridas.

Ao passo que aquelas reivindicadas por Garcia Paes Leme, inicialmente concedidas, foram revogadas sem um critério objetivo. Desta forma, percebe-se que, além da desobediência das normas do Alvará de 1795, havia na concessão de sesmarias um interesse político e territorial. Naquele período, surgiram inúmeras denúncias junto à Coroa Portuguesa contra as arbitrariedades perpetradas pelos administradores da concessão de sesmarias, governadores e capitães-generais.

Ainda neste contexto, destaca-se a sesmaria concedida a Manoel de Borba Gatto, na capitania de Minas, em que, de maneira expressa, mencionava que "a qualidade e merecimento do dito Tenente General pelo bem que tem servido a sua Majestade nesta conquista" (FONSECA apud VARELA, 2005, P. 96). Resta claro o interesse político dos administradores da província quando da concessão das sesmarias.

Ademais, os dados apresentados por Maria Amélia Garcia de Alencar (1993) revelam que a maioria daqueles que registraram suas terras em Goiás, após a lei de terras, o fez se declarando comprador de posse ou sesmarias e não como sesmeiro. Também, em Goiás, ocorreram só a confirmação de 14 sesmarias, ou seja, num estado conhecido pela presença do latifúndio, as sesmarias tiveram pouco impacto na definição da propriedade da terra.

Desta forma, não obstante as fundadas considerações tecidas por grandes estudiosos da tese de que o quadro latifundiário brasileiro é fruto do regime das sesmarias, ainda que seja apenas para reflexão, afigura-se pertinente o contraponto, no sentido de que, embora seja irrefutável que o latifúndio foi estruturado à época colonial, o modelo jurídico sesmarial é farto em legislações que buscaram regularizar a concessão de sesmarias em parcelas de territórios consideradas razoáveis, destinadas ao cultivo e moradia habitual.

Todavia, estas pretensões não se consagraram vitoriosas diante dos interesses mercantilistas e políticos da província, na medida em que, na condição de responsáveis pela 
tramitação dos processos da concessão de sesmarias, agiam de modo de perpetuar o poder da elite colonial sobre os pequenos sesmeiros. Portanto, diante dos fatores elencados, seria injustificado atribuir ao sistema jurídico-normativo das sesmarias a constituição do latifúndio.

\section{CONCLUSÃO}

Diante dos apontamentos expendidos no presente trabalho, demonstrou-se que o regime de sesmarias, originalmente português, foi instituído no Brasil de maneira distinta daquela como ocorreu na metrópole em decorrência da intenção de colonizar as terras da colônia.

A pesquisa possui como enfoque a análise do conjunto normativo que alicerçou todo o período sesmarial, uma vez que, enquanto instituto jurídico, regulamentou as relações advindas da distribuição de terras da época colonial, motivo pelo qual se revela importante para o a investigação da constituição do latifúndio.

O sistema das sesmarias foi composto por várias leis representadas por alvarás, decretos e regulamentos que foram alteradas à medida da transformação da conjuntura social, política e econômica em que o Brasil-colônia enfrentava. Entre estas mutações, podemos citar algumas imposições da metrópole que foram comuns em suas legislações: o dever de moradia habitual e, principalmente, os deveres de cultivo e demarcação de terras.

Observa-se, pois, que a intenção do legislador português não foi perpetuar e legitimar a ocupação de grandes parcelas de terras, como comumente acontecia na época colonial. Em verdade, ainda que a pretensão de impor a demarcação de terras não fosse para evitar a desigualdade entre os sesmeiros, a metrópole buscava exercer o seu poderio sobre toda a colônia por meio da delimitação dos territórios cedidos, o que, mesmo que por via oblíqua, corrobora com a ideia de que da legislação das sesmarias não foi subsídio legal de proteção ao latifúndio.

Acresça a isso a ineficácia da fiscalização por parte da administração da colônia das sesmarias concedidas. Como relatado por Motta (2012), não havia a preocupação em inspecionar a forma de utilização da terra, o cumprimento dos deveres jurídicos de demarcação, cultivo, moradia habitual. A posse de grandes parcelas de terras era condição para a manutenção do modo de produção e utilização da mão-de-obra escravocrata adotada no Brasil-colônia. Ademais, após a extinção das sesmarias, foi constatado que grande parte do território brasileiro ainda não havia sido apropriado. 
A análise do latifúndio, na perspectiva proposta no presente trabalho, preleciona que sua constituição ocorreu na época da vigência do regime de sesmarias, mas as normas que regulamentaram o referido período histórico não são a causa da sua existência, pois, como visto, o favorecimento político e econômico que orientava a concessão das sesmarias e outros fatores citados impediam a eficácia das legislações tendentes a restringir e prescrever normas entendidas como obstáculos à concessão de sesmarias sem obediência aos critérios legais.

\section{REFERÊNCIAS}

ALCANTARA FILHO, J.L. \& FONTES, R. M. O. A formação da propriedade e a concentração de terras no Brasil. Revista de História Econômica \& Economia Regional Aplicada - Vol., 4 No 7, Jul-Dez 2009. Disponível em: Acesso em: 20 agosto 2018;

ALVEAL, Carmen Margarida de Oliveira. Identidades e conflitos: convertendo terra em propriedade do mundo Atlântico português. Séculos XVI-XVIII. Tese de Doutorado em História - Johns Hopkins University, 2007;

BENATTI, José. Direito de Propriedade e Proteção Ambiental no Brasil: apropriação e o uso dos recursos naturais no imóvel rural. Tese de Doutorado em Direito - UFPA, 2003;

CASTRO, Hebe Mattos de. Ao sul da história. São Paulo: Brasiliense, 1987;

COSTA, Emília Viotti da. Da monarquia à república: momentos decisivos. 6a Ed. São Paulo: Fundação Editora da UNESP, 1999.

PORTO, Costa. O sistema sesmarial no Brasil. Brasília: Universidade de Brasília, 1965;

FERLINI. Vera Lúcia Amaral. O mito do latifúndio. In: Açúcar e colonização. São Paulo: Alameda, 2010, p. 211-213;

FILHO, Roberto Lyra. O que é Direito. Coleção Primeiros Passos 62. São Paulo: Ed. Brasiliense, 1999;

GORENDER, Jacob. Regime Territorial no Brasil escravista. In: O Escravismo Colonial. $5^{\circ}$ ed. rev. e ampl. São Paulo: Ática, 1988;

GROSSI, Paolo. História da propriedade e outros ensaios. São Paulo, Renovar, 2006;

GUIMARÃES, Alberto Passos. Quatro Séculos de Latifúndio. $4^{\circ}$ ed. Rio de Janeiro: Paz e Terra, 1977;

HOLLANDA, Sérgio Buarque. Raízes do Brasil. 4ª ed. Brasília: Unb, 1963;

LIMA. Cirne Ruy. A pequena história territorial do Brasil: sesmarias e terras devolutas. $5^{\mathrm{a}}$ ed. Goiânia - GO: UFG. 2002; 
LOUREIRO, Francisco Eduardo. A propriedade como Relação Jurídica Complexa. Rio de Janeiro: Renovar, 2003;

MOTTA. Márcia Maria Menendes. A Lei de Sesmarias e a ocupação colonial: sobre as leis. In: MOTTA. Márcia; ZARTH, Paulo (Orgs.). Direito à terra no Brasil: a gestação do conflito 1795-1854. São Paulo: Alameda, 2012, p. 129-197;

Nas fronteiras do poder: conflitos de terra e direito agrário no Brasil de meados do século XIX. Tese (Doutorado em História) Campinas: UNICAMP, 1996;

RAU, Virgínia. Sesmarias medievais portuguesas. Lisboa: Editorial Presença, 1982;

SANCHES, Marcos Guimarães. As sesmarias no processo de colonização: nota prévia da pesquisa. REUNIÃO DA SOCIEDADE BRASILEIRA DE PESQUISA HISTÓRICA, 16, 1996, Curitiba, Anais;

SILVA, Ligia Maria Osorio e SECRETO, Maria Veronica. Terras públicas, ocupação privada: elementos para a história comparada da apropriação territorial na Argentina e no Brasil. In: Economia e Sociedade. Campinas (12):109-41, jun 1999;

SILVA, Lígia Osório. O sesmarialismo; $O$ fim das sesmerias e $O$ predomínio da posse. In: . Terras Devolutas e Latifúndio. 2a ed. Campinas: Editora Unicamp, 2008. 41103 ;

SMITH, Roberto. A transição no Brasil: a absolutização da propriedade fundiária. In: Propriedade da terra \& transição: Estudo da formação da propriedade privada da terra e transição para o capitalismo no Brasil. São Paulo : Brasiliense, 1990;

THOMPSON, E. P. Costume, lei e direito comum. In: Costumes em comum: estudos sobre a cultura popular tradicional. São Paulo: Companhia de Letras, 1998, p. 86-149;

TRECCANI, Girolamo. Violência e grilagem: instrumentos de aquisição da propriedade da terra no Pará. Belém: UFPA, ITERPA, 2001;

VARELA. Laura Beck. Das Sesmarias à Propriedade Moderna: Um Estudo de História do Direito Brasileiro. Rio de Janeiro: Ed. Renovar, 2005;

WOLKMER, Antônio Carlos. Fundamentos da História do Direito. Belo Horizonte: Del Rey, 2002. 